\title{
HIERARQUIA POR TODO LADO: uma análise da hierarquia militar no espaço universitário e seus desdobramentos ${ }^{1}$
}

\author{
HIERARCHY EVERYWHERE: \\ an analysis of the military hierarchy in the university space and its consequences.
}

JERARQUÍA EN TODAS PARTES:

un análisis de la jerarquía militar en el espacio universitario y sus consecuencias

\author{
Érika Guimarães Ferreira \\ Mestre em Sociologia e Direito \\ Universidade Federal Fluminense \\ fguimaraes.erika@gmail.com \\ Brasil \\ ORCID 0000-0002-9026-6173 \\ Perla Alves Bento de Oliveira Costa \\ Doutoranda em Sociologia e Direito \\ Universidade Federal Fluminense \\ perlafem@hotmail.com \\ Brasil \\ ORCID 0000-0001-5227-4124
}

\section{Resumo}

Este trabalho discute, a partir da observação participante, a hierarquia militar e a acadêmica, a partir de experiências vivenciadas e observadas no âmbito do Curso de Tecnólogo em Segurança Pública e Social. A inserção de agentes de segurança pública na universidade, trouxe para o ambiente acadêmico, diversos conflitos decorrentes das socializações militar e universitária próprias da forma diferenciada de hierarquização dessas duas instituições.

Palavras-chave: hierarquia; polícia militar; universidade

\footnotetext{
${ }^{1}$ Paper originalmente apresentado no Grupo de Trabalho 18, intitulado «Profissões jurídicas, rituais judiciários, sistema de justiça e pesquisa empírica em direito em diálogo com a antropologia», do VI ENADIR (Encontro Nacional de Antropologia do Direito), ocorrido entre 26 e 29 de agosto de 2019 na FFLCH-USP (Faculdade de Filosofia, Letras e Ciências Humanas da Universidade de São Paulo).
} 


\begin{abstract}
This paper discusses, based on participant observation, the military hierarchy and the academic from experiences and observed within the scope of the Technologist Course in Public and Social Security. The insertion of public security agents in the university, brought to the academic environment, several conflicts arising from the military and university socializations proper to the differentiated hierarchical form of hierarchy of these two institutions.
\end{abstract}

Keywords: hierarchy; military police; university.

\title{
Resumen
}

Este artículo discute, a partir de la observación participante, la jerarquía militar y la académica a partir de experiencias y observadas en el ámbito del Curso de Tecnólogo en Seguridad Pública y Social. La inserción de agentes de seguridad pública en la universidad, trajo al ámbito académico, diversos conflictos derivados de las socializaciones militares y universitarias propias de la diferente forma de jerarquización de estas dos instituciones.

Palabras clave: jerarquía; policía militar; universidad. 


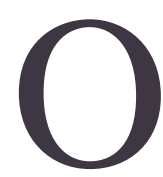

presente artigo apresenta reflexões acerca da hierarquia militar no âmbito universitário.

Tais reflexões são oriundas da participação observante da socialização acadêmica dos alunos do Curso de Tecnologia em segurança Pública e Social.

Oferecido pela Universidade Federal Fluminense através da Fundação Centro de Ciências e Educação Superior a Distância do Estado do Rio de Janeiro Fundação CECIERJ/CEDERJ, o Curso de Tecnologia em Segurança Pública e Social surgiu para atender a uma solicitação da Secretaria de Estado e Segurança (SESEG). É oferecido na modalidade semipresencial e, por exigência do Ministério da Educação (MEC), atende exclusivamente aos profissionais da ativa da segurança pública. Até o primeiro semestre de 2018, $80 \%$ (oitenta por cento) das vagas eram destinadas a policiais civis e militares do Estado do Rio de Janeiro, em razão da demanda da SESEG e 20\% (vinte por cento) destinados aos demais "profissionais das carreiras de segurança pública", como dispõe o catálogo de cursos superiores de tecnologia do MEC.

O processo de formação dos profissionais de segurança pública, até meados de 2012, era norteado apenas pela Secretaria Nacional de Segurança Pública, sendo este um ensino institucional. A idealização de um curso formal e, portanto, acadêmico, destinado exclusivamente aos profissionais atuantes diretamente com a Segurança Pública surgiu a pedido do Governo do Estado.

\section{Sobre a formação policial}

Como apontam Caruso, Patrício e Pinto (2006), a produção acadêmica sobre formação policial é recente no Brasil, principalmente no que tange a compreensão dos mecanismos de atualização e estratégias para transmissão e assimilação de novos conhecimentos. Além disso, é importante destacar a qualidade e os objetivos intrínsecos aos processos de formação desses profissionais pelas agências de segurança pública. As autoras explicam que o grau de importância dada à formação na Polícia Militar do Estado do Rio de Janeiro (PMERJ) deve ser compreendido dentro de um contexto e não isoladamente tendo em vista a qualificação profissional e a demanda operacional. Além disso, apontam para o fato de ser evidente que a formação não é prioridade institucional, “... a PMERJ opera no curtíssimo prazo, buscando responder a demandas emergenciais de ampliação de seus quadros, traduzindo-se, como muitos de seus integrantes relatam, numa "fábrica de produzir soldados". (CARUSO, PATRÍCIO e PINTO, 2006, p.14) 
Segundo Kant de Lima (2007), “a formação dos policiais tem que incluir processos de socialização acadêmica e profissional" (p.82). Aponta, desta forma, para uma formação que instigue a pesquisa de políticas em segurança pública e privilegie a administração de conflitos contrária à repressão.

Desta forma, neste âmbito de atuação, a educação se apresenta como uma forma de exclusão e não de inclusão. Isso porque, os mais qualificados acabam ficando à margem em suas atividades, visto que a instituição não demonstra interesse por esse tipo de qualificação. Essa consideração tem como base o fato de haver, nas corporações, uma distinção entre os que têm formação e os que não tem. Os que não possuem formação são mais obedientes, enquanto os que a possuem questionam com maior frequência.

Nas corporações, tal distinção relaciona-se à relação de poder estabelecida entre os que têm formação e os que não têm. $\mathrm{Na}$ hierarquia militar, esse poder pode ser identificado de duas formas. Primeiramente pela ameaça ao poder ora institucionalizado e definido, ou seja, uma ameaça real e intelectual para aquele que detém o poder institucional e real, conforme ingresso e patente. Mas que, nem sempre, possui uma formação acadêmica, tão pouco uma formação especializada, como seria o caso dos alunos egressos do Curso de Tecnologia em Segurança Pública e Social.

Os alunos relatam situações em que seus superiores explicitam que a formação acadêmica não altera em nada sua relação com esses na instituição. Em uma tutoria um aluno relatou que seu superior teve a seguinte fala: "Pode fazer esse cursinho aí e achar que é o sabe tudo. Eu não tenho e nem preciso ter por que aqui dentro quem manda, com curso da área ou não, sou eu”.

Pode-se, por outro lado, pensar no poder que é exercido, durante as tutorias, sobre aqueles que, com patentes diferentes, estão fazendo o curso. Há um poder coercitivo e intimidador exercido por seus próprios colegas de classe, que em alguns momentos são seus superiores, como forma de vigiar e punir aquele que de alguma forma se distanciar das regras definidas pela instituição ou que as coloque em questão.

Nesse contexto, Foucault (2006) destaca a necessidade de se limitar o poder soberano e, assim, definir o limite para o exercício do poder conservando sua legitimidade. Foucault apresenta uma metáfora que pode ser utilizada para descrever tal situação: "Em suma, inverte-se o princípio da masmorra, a luz e o olhar de um vigia captam melhor que o escuro, que, no fundo, protegia" (p.129). O aluno por vezes, em função dessa prática repressiva entre os seus, exerce a prática da obediência como fruto da 
repressão, da ignorância e da não concordância.

Por grande parte dos alunos, apresenta-se, como defesa às práticas repressivas, a ideia de que é na rua que se aprende a ser policial e que teoria e prática são questões que não se relacionam. Essa contraposição define-se como estratégia para distanciar o que é aprendido formalmente e o que é exercido na prática (CARUSO, 2004). A autora ainda apresenta, como ponto relevante para a discussão da formação acadêmica dos agentes de segurança pública, o fato de ser a prática de uma formação reflexiva, algo muito recente.

O processo de formação dos agentes de segurança pública, em sua maioria, constitui-se como espaço instrucional e não de conhecimento. Além disso, a formação inicial e institucional desses agentes pode ser analisada sob diversos aspectos.

Primeiramente, podemos fazer referência ao tipo de formação recebida por estes nas Academias de polícia. O currículo, como aponta Oberling (2011) é baseado em disciplinas que reforçam as rotinas $\mathrm{e}$ hierarquias militares. Segundo a autora "são baixos os investimentos disciplinares de cunho humanístico (sociologia, criminologia e filosofia) que possibilitem ao policial militar a compreensão do mundo contemporâneo, seus problemas e vicissitudes". (OBERLING, 2011, p.82)
Distintamente, no Tecnólogo em Segurança Pública (TSP), privilegia-se a construção do conhecimento a partir da interlocução entre sujeitos, com base em disciplinas elaboradas por pesquisadores das áreas de Sociologia, Antropologia, Ciência Política, entre outras que apresentem também esse viés. Nos cursos de formação das agências, dado o seu currículo, o ensino instrucional sem reflexividade sobre as práticas propõe a segurança pública de forma repressora, sendo o objetivo principal de seus agentes acabar com o conflito.

A partir desse ponto de vista, é possível fazer relação com um dos conflitos apresentados no curso: os alunos almejarem um tratamento que os perceba como os alunos dos demais cursos, embora suas atitudes demonstrem e clamem por um tratamento diferenciado a todo o momento. Apesar de buscar o contrário na Universidade, em sua maioria, reproduzem o autoritarismo presente no dia a dia de sua prática profissional. Geraldo e Kant de Lima (2015) apresentam dois obstáculos que devem ser considerados no processo de socialização universitária: a falta de identificação com a autoridade acadêmica e a supremacia da socialização na Polícia Militar, onde a prática supera a teoria.

O incômodo dos alunos nos momentos de realização das avaliações presenciais é facilmente observável, pois, não estão sob a 
supremacia de suas instituições profissionais, mas submetidos à regras e normas da instituição acadêmica. Subjacente a este incômodo está uma aparente pergunta: "Afinal, quem são os tutores para dizer o que eles podem ou não fazer"? Quanto mais se reflete sobre o curso, seus atores e a segurança pública como processo social e não um lugar físico de manutenção, mais conflitos são identificados.

Kant de Lima (2010) explica a lógica do contraditório como um processo de construção da verdade, próprio a algumas tradições judiciárias e acadêmicas. Essa lógica consiste na criação de uma infinita oposição entre teses necessariamente contraditórias. Em defesa de um saber da prática em contraposição às reflexões teóricas acadêmicas, os alunos utilizam-se dessa lógica como estratégia.

Segundo Geraldo e Kant de Lima (2015), “a articulação da lógica do contraditório com o recurso à experiência serve para desqualificar os conteúdos das disciplinas, impedindo-os de incorporar as formas acadêmicas de construção de consensos" (p.15). O que o autor aponta como consequência da dificuldade em assimilar e aprender conteúdos divergentes com sua opinião.

Cabe, neste momento, fazer um breve esclarecimento sobre a lógica do contraditório. Sob esta lógica, o argumento da autoridade corresponde à autoridade que não precisa de argumentos para fazer valer seu lugar de poder, em uma relação instituída e em fenômenos que acontecem cotidianamente.

A forma de produzir verdades está, segundo Kant de Lima (2017), relacionada ao sistema de provas reais. A produção de verdade jurídica que, antigamente e em outras culturas, tinha relação com a verdade divina passou a conviver com o inquérito, onde, ao invés de deuses, são as testemunhas que determinam a verdade dos fatos.

No caso do conhecimento científico, a verdade dos fatos encontra-se associada à ideia de igualdade dos interlocutores a partir da contextualização e da autoridade do argumento. No entanto, em um contexto brasileiro, na qual a sociedade é hierarquizada, os interlocutores não estão em igualdade de poder impedindo a interlocução e a argumentação. Desta forma, os argumentos científicos precisam de uma caracterização empírica. Neste contexto, o consenso da interlocução entre os iguais é substituído pelo consenso da empiria. Consequentemente "permitem formas de analisar, com foco na empiria, a dimensão dos desafios envolvidos nesta proposta pedagógica do curso de Tecnólogo em Segurança Pública e Social”. (VERÍSSIMO.p.12)

O curso de Tecnologia em Segurança Pública e Social está inserido em uma sociedade hierárquica com intermediários 
detentores de um poder oriundo de um saber particularizado. A Educação à Distância se insere dentro de uma tradição hierárquica que precisa de mediadores para transmitir o conhecimento, é preciso uma autoridade, nesse caso, os tutores, para a transição desse conhecimento. Nesse caso, o conhecimento é poder e o que prevalece é a autoridade do argumento.

As referências em termos de conhecimento dos policiais militares, maioria entre os alunos do curso não estão pautadas no conhecimento científico e, sim, na hierarquia militar onde os fatos são determinados pela autoridade. Nesse contexto, é que vai se discutir essa diferenciação do saber científico e do saber prático, além de, se instaurar o processo de socialização acadêmica.

Podemos, a partir dessas considerações, fazer referência ao que Veríssimo (2015, p.8) categoriza como "choque cultural". O autor aponta que, ao difundir um conhecimento crítico, não apenas sob a ótica do Estado, mas também sob a perspectiva da sociedade, originam-se conflitos oriundos do contraste entre o ethos militar e o ethos da universidade. Isto se dá devido ao ingresso, na universidade, não como militares que possuem expectativas distintas ao que é oferecido pelo curso, mas como alunos. O estranhamento à metodologia e ao conteúdo de um curso com essa perspectiva se configura como o momento do "choque cultural", termo usado pelos alunos para definir o que sentiam com relação ao Curso de "Tecnólogo", sendo entre tantas outras variáveis, o estranhamento causado pelo conteúdo das disciplinas elemento chave para o "choque cultural".

Via de regra, em sua formação institucional, o aluno matriculado no Tecnólogo se tornou policial a partir de instruções e treinamentos - situação expressa na fala da aluna durante um seminário. Iremos nos deter ao fato de que, tendo como cultura algo que se apresenta como distinto aos conteúdos disponibilizados no curso, é com esse ethos internalizado que as fronteiras identitárias são definidas e reforçadas.

Esta questão não se apresenta como um problema ao projeto pedagógico do curso. Ao contrário, apresenta-se como objeto de realização por parte de seus idealizadores, uma vez que refletir sobre os paradigmas corporativos e naturalizados (VERÍSSIMO, 2015) é uma experiência esperada. Portanto, chamaria esse processo de uma pedagogia da reflexividade, pois estimula uma reflexão sobre seu lugar no mundo social a partir do ponto de vista do outro, aqui representado pelas pesquisas em ciências sociais. Isto porque tais pesquisas não reproduzem os pontos de vista dogmático-repressivo, próprios dos operadores do direito, e militaristaestratégico, próprios dos profissionais das 
carreiras de segurança pública, fazendo com que suas fronteiras identitárias, mesmo que presentes em função de um estranhamento, possam produzir reflexão.

Há um discurso de "inclusão social" proferido pelo Consórcio CEDERJ/CECIERJ em seu processo de interiorização da Universidade Pública, que consiste em Tecnologia social de relevância e êxito. De forma distinta aos demais cursos do Consórcio, tal discurso não tem, nos alunos do Tecnólogo, sujeitos com problemas de “exclusão social”. São, em razão da especificidade do curso, profissionais inseridos no mercado de trabalho. Em contrapartida, o aluno do Tecnólogo se insere no contexto de "inclusão social" sob outra perspectiva. Como aponta Veríssimo (2015) "o "choque cultural" decorre, não da "exclusão social" do aluno, e sim de sua inclusão social, pessoal, psíquica e corporativa, na categoria de Policial". (p.19)

Como instrumento de análise das Tecnologias sociais, podemos tomar o fato de a Segurança Pública funcionar como força de controle social na sociedade como um todo e, internamente, nas agências e instituições de segurança, além de possibilitar reflexões sobre os dilemas da Educação Superior nas sociedades contemporâneas e desiguais (VERÍSSIMO, 2015).

Observa-se a partir da análise da experiência descrita e do discurso do diretor da divisão de ensino: “(...) é importante ter policiais qualificados" que, a teoria e a prática são contraditórias. Além de sugerir que tais policiais sejam uma ameaça à hierarquia institucional e aos propósitos históricos de sua atuação repressiva e pouco reflexiva.

O fato de as instituições de segurança pública, em sua maioria, não reconhecerem os alunos que estão se formando, ou mesmo os que já se formaram, reflete na insatisfação dos mesmos e na desmotivação para que outros profissionais se qualifiquem. $\mathrm{O}$ que, antes era objeto a ser alcançado, tem atualmente uma procura menor. Como pode ser observado em mensagem de um aluno formado no curso:

"Infelizmente a nossa instituição não vem aproveitando os graduados em segurança pública. Desanimando alguns colegas. Triste realidade. Muitos estavam fazendo com essa expectativa. A minha visão vai muito além de pensar somente intramuros. Eu não me preocupo com essa visão institucional porque sei que o município é muito ligado à política e se a gente entrar achando que é dever do município e gestor dar essa oportunidade vamos nos decepcionar. [...] Hoje o que vemos é o município brincar de polícia municipal. [...]Falta desde investimentos no indivíduo quanto na estrutura institucional. Guardas sem espaço físico para funcionar administrativamente $e$ operacionalmente. Muitas sem lei de criação. Muito complicado."(mensagem de aluno formado no curso, atuante na guarda municipal, 2017). 
A procura pelo curso assim que começou a ser ofertado era muito grande, por alguns motivos. Alguns alunos pensavam que se tratava de um curso instrucional. Havia a cogitação, em função de ações da Secretaria de Segurança Pública como a própria criação do curso, de que o Tecnólogo seria uma das formas de acesso ao oficialato. $\mathrm{O}$ que não ocorreu. $\mathrm{O}$ concurso de ingresso de oficiais é exclusivo para bacharéis em Direito. Tal decisão demonstra, por parte da instituição, que o que poderia ser um processo de valorização profissional e a certeza de agentes cada vez mais qualificados excluem os seus e corrobora para a ideia de que não lhes é interessante ter profissionais reflexivos e qualificados. Como aponta Kant de Lima (2013):

Na Polícia Militar, por um lado, temos duas entradas na profissão, que correspondem à formações e funções diferenciadas, uma para oficiais, outra para praças, sendo que estes dificilmente chegam aos postos mais altos do oficialato; na Polícia Judiciária, temos várias carreiras, mas a principal distinção, de ordem salarial, se verifica entre os delegados - que, embora servidores do Executivo, clamam ver sua carreira incluída entre as chamadas carreiras jurídicas próprias dos operadores do Poder Judiciário. (KANT DE LIMA, 2013, p.563)

Essa pretensão se apresenta há bastante tempo. Em 2009, por exemplo, foi realizado um Seminário para debater o curso mais adequado para ingresso ao oficialato. Na ocasião, 73,03\% (setenta e três inteiros e três décimos percentuais) dos participantes optaram pela exclusividade dos egressos dos cursos de bacharel em Direito. Segundo Araújo (2009) ter este requisito como ingresso ao oficialato é essencial, por tornála uma carreira jurídica de estado, uma vez que estes profissionais são, de fato, operadores do Direito.

A essa questão de correlação do curso de Direito à função de oficial, podemos ainda fazer algumas análises. Primeiramente, a de que as disciplinas jurídicas nos cursos de formação militar se configuram como consequência do regime democrático no Brasil (SILVA, 2011 e MUNIZ, 1999) sendo utilizada, no entanto, como forma de constituir a identidade militar e reforçar a noção de hierarquia. Fernandes (2017) faz referência a esse viés jurídico nos cursos de formação:

Silva (2011) e Muniz (1999) atribuem a presença das disciplinas de direito no currículo dos cursos de formação, como uma consequência da instauração do regime democrático no Brasil, que trouxe como uma das consequências, além da promulgação da Constituição Federal Brasileira de 1988, a modificação do currículo da polícia, no intuito de desconstruir a imagem de uma polícia autoritária e abusiva construída no período de regime ditatorial. Em contrapartida, as disciplinas jurídicas e, as disciplinas militares tem o intuito de produzir nos alunos o espírito de corpo, Castro (1963), a identidade militar, que 
compreende principalmente a noção de hierarquia. A hierarquia, nesse sentido, será responsável por garantir a ordem nos cursos de formação, assim no ambiente militar ordem e obediência significam o reconhecimento da autoridade, e principalmente, como demonstra Silva (2011) a obediência. (FERNANDES, 2017, p. 30)

Nessa mesma vertente, Oberling (2011) fazendo referência ao viés jurídico presente na formação dos oficiais militares, aponta ainda para o conflito estrutural que se faz presente. Em sua concepção, a prioridade da formação militar sobre a formação policial não está restrita apenas aos praças. A contradição entre uma socialização com cunho militar, com forte viés jurídico e outra destinada ao mundo das ruas também estão presentes na formação dos oficiais militares. "Esse paradoxo aparece como um "conflito estrutural" da instituição militar, presente em toda a trajetória do oficial da PMERJ". (SILVA, 2009 apud OBERLING, 2011, P.84)

O conhecimento dos policiais, oficiais, estão referenciadas pelo Direito. Ressalta-se que este conhecimento, profundamente marcado pelo contraditório, no Brasil, tem sua lógica diferente.

\section{A ausência de protocolos e a diferença entre transgredir regras ou ordens}

O poder de tomada de decisão, diferentemente do conhecimento científico, é de uma autoridade com poderes inclusive de criar os fatos. Nesse contexto de poder, na hierarquia militar, o que vale é a autoridade de quem tem o poder de dizer o que é verdade ou não. Não há ponderação, um manda e o outro faz. Nesse caso, o conhecimento pautado no Direito, também é determinante.

Os protocolos são frutos de consenso. No Brasil, no entanto, apesar de existirem protocolos estabelecidos, principalmente, nas instituições militares hierarquizadas, estes são normas abstratas interpretadas por alguém que tem o poder.

Em diversas situações, os alunos se utilizam da hierarquia para demandar privilégios e não direitos, quando, por exemplo, solicitam intervenção de superiores dos tutores para exigirem uma ação de alguém que, segundo a visão deles, tem mais poder e, consequentemente, manda mais. Essa utilização da hierarquia ocorre por uma confusão estabelecida, por eles, com a lógica hierárquica militar. Como Neves (2016) a socialização da polícia militar baseia-se em princípios e valores pautados na hierarquia e na disciplina, o que pressupõe dar lugar a uma nova identidade, de cunho militar, excluindo valores civis. Segundo Silva (2013) a hierarquia é um princípio de organização, apontando quem deve obedecer e quem deve mandar. Sobre a 
hierarquia da universidade Neves aponta que "a hierarquia universitária tem a ver com o princípio da liberdade acadêmica, que só deve ser limitada pelos seus pares, não como nas instituições militares que respeitam a cadeia de comando". (GERALDO; KANT, 2015 apud NEVES, 2016, p.26)

A confusão estabelecida entre a hierarquia militar e a acadêmica é explicitada por Kant de Lima em um artigo escrito para o Jornal O Globo:

[...] uma das dificuldades maiores que tínhamos e temos era que eles entendessem que, diante dos conflitos cotidianos que se estabeleciam normalmente entre professores e alunos, embora não houvesse nenhum comandante cuidando para que a ordem fosse mantida, a Universidade tinha regras claras, construídas por seus diversos Conselhos - que detém representações de todos os seus segmentos técnico-administrativos, professores e estudantes - e que são de adesão obrigatória àqueles que nela se matriculam. [...] esta ordem universitária institucional não era empiricamente visível e eles frequentemente queriam dirigir-se ao ou falar com o Reitor - que eles pensavam ser o nosso comandante - para resolver suas queixas escolares e fazer valer seus supostos direitos. (KANT DE LIMA, 2019)

Outro exemplo de transgressão às regras ocorre quando se colocam na posição de diferente dos demais alunos de outros cursos. Em função de suas atividades, realizadas em sua maioria em escala de serviço, vão se apresentar como alunos especiais e, portanto, detentores de direitos diferenciados. Buscando privilégios e demonstrando a dificuldade que esses alunos têm em exercitar a alteridade.

Quando exigem o direito de realizar a avaliação presencial após o horário máximo estabelecido para a entrada do aluno em sala de aula; ou exigem entrega do material didático fora do horário de funcionamento da secretaria; ou mesmo quando dizem que irão ao seminário, com carga horária de dez horas, apenas para assinarem a lista de presença para receberem o certificado de participação mas, que só poderão ficar uns 15 (quinze) minutos na atividade, se distanciam do discurso tão presente sobre o respeito às regras.

Os alunos experimentam as regras em diversas situações, mas as regras nas instituições de segurança pública são mais rigorosas, pois, quando há a transgressão, a punição recai sobre o corpo do policial, que pode ficar preso administrativamente. Diferentemente do que ocorre na Universidade, já que as sanções administrativas são anotações em seus registros, que não o impedem de frequentar a universidade. Apesar disso, os alunos interpretam as sanções como castigo.

Nos processos de interação social, é necessário que as expectativas relativas às normas sejam sustentadas. Isso ocorre a 
partir da incorporação de seus significados.

Esse processo de medidas restauradoras pode ser verificado em uma situação ocorrida no segundo semestre de 2015. Em função do vazamento das questões referentes a Avaliação Presencial 2 (AP2) de uma disciplina, ela foi anulada. A anulação corresponde a uma medida para reparar um dano causado por uma transgressão à regra institucional. Transcrevo parte de um e-mail enviado pela coordenação aos alunos que demonstra essa intenção de reparação.

A anulação da prova prejudicou a todos. Porém, foi unânime entre os Coordenadores de Curso, a Coordenação da disciplina e as Diretorias. Comparativamente, podemos pensar nas provas de concurso, onde o vazamento da prova obriga todos os candidatos a refazerem a prova, ou mesmo no ensino presencial quando $\mathrm{o}$ professor tem notícia dessa prática, a prova é anulada.

Essa decisão não partiu apenas do Coordenador, mas procura resguardar a colegialidade das decisões e, principalmente, a institucionalidade das regras da Universidade. Há uma diferença entre a obediência às regras $\mathrm{e} a$ obediência às ordens. Longe de ser arbitrária, essa decisão é informada pelas regras e pelas razões explicitadas de forma transparente. As relações da vida civil na Universidade são orientadas pelas regras que nos constrangem. A hierarquia fundada na cadeia de comando se constitui em função da obediência às ordens. A ausência de ordens na vida civil não significa uma desordem. Por isso, a reivindicação dos privilégios, ou uma atenção particular, desiguala uma relação entre iguais perante às regras de convivência da vida civil. Pretendemos que todos possam se socializar com a responsabilidade perante a essas regras $\mathrm{e}$ as consequências negativas de sua inobservância que afetam a todos....

Nós não pretendemos tratar essas questões em termos de ilícito, culpa e punição. Nós assumimos a responsabilidade institucional de explicitá-la para uma reflexão coletiva. Expurgar o culpado e as eventuais conivências não modifica nossas práticas. (COORDENAÇÃO DO CURSO, 2015)

Muitos alunos entraram no curso com a expectativa de confirmar o que aprenderam na prática diária no exercício de suas funções. Ao iniciar o curso, eles se depararam com discussões complexas sobre a Segurança Pública do ponto de vista da sociedade e a forma ampla que constroem as diferentes concepções de sociedade, assim como os fatores envolvidos nessa construção.

$\mathrm{O}$ confronto das moralidades civil e o ethos policial se inicia desta forma. $\mathrm{Na}$ proposta do curso e em sua metodologia, se pluralizam ao longo do curso e na relação de ensino e aprendizagem.

Diferente da concepção de hierarquia presente nas instituições militares - como princípio de organização, disciplina e punição - na universidade, funciona de forma horizontal como aponta Geraldo e Kant de Lima (2015): 
na universidade, essa hierarquia é administrativa e está subordinada ao princípio da liberdade acadêmica, que só pode ser limitada pelos próprios pares, e não a uma hierarquia de comando único. $\mathrm{O}$ aluno não consegue achar uma correspondência entre as representações da hierarquia militar e a hierarquia universitária e conclui que na universidade não há hierarquia alguma. A outra questão é a disciplina que é compreendida como obediência pelas corporações de segurança pública. A disciplina para a universidade é o enquadramento nas regras da instituição, que incluem formas de tratamento entre os pares e entre os três segmentos da universidade, professores, técnicoadministrativos e alunos. (GERALDO e KANT DE LIMA, 2015, p.08)

Os alunos são oriundos desta forma diferenciada de hierarquia e regras: uma hierarquia das instituições militares em que, conforme relato de um aluno, "manda quem pode e obedece quem tem juízo. Na polícia não tem questionamento, diálogo. É tudo muito organizado e ordenado. A gente só obedece".

A Universidade, no entanto, lida com a hierarquia e com a disciplina de forma distinta. Essa forma distinta de compreensão desses significados, gera alguns conflitos no âmbito acadêmico. Neste sentido, a disciplina é um princípio da obediência, indicando a forma e a intensidade desta na relação entre os subordinados e seus superiores, sendo assim "obedecida, respeitada e temida" (NEVES, 2016). Em contrapartida, a noção de disciplina, na universidade, diz respeito às regras institucionais sobre as formas de tratamento entre os que estão inseridos neste ambiente. "A disciplina está ligada às formas que o aluno desenvolve para atender e compreender cada conteúdo. (GERALDO; KANT, 2015, apud, NEVES, 2016, p.26)

O processo disciplinar é exercido pela hierarquia militar em todos os momentos da vida do policial, desde sua formação inicial, nas academias de polícia até o seu dia a dia profissional. Não é de se estranhar, portanto, que haja frases como: "Você tem direito a não ter direito e a não reclamar dos direitos que não tem" (Instrutor do Curso de Formação de Soldados, apud, COSTA, 2018, p.40).

Como aponta Foucault (2006), a disciplina é uma forma de controle social por parte daquele que detém o poder. Ressaltando que a disciplina não é um aparelho ou uma instituição e sim, funciona como uma rede sem fronteiras, "trabalha o corpo dos homens, manipula seus elementos, produz seu comportamento, enfim, fabrica o tipo de homem necessário ao funcionamento e manutenção da sociedade industrial, capitalista. (FOUCAULT, 2006 apud FERREIRA, 2019, P.104)

Como é possível perceber na citação do autor, a disciplina, nesse caso, se 
configura como instrumento de poder que, nem sempre é físico ou perceptível, mas recai sobre o corpo daquele a quem se quer controlar. No caso dos policiais militares, uma "disciplina que condiciona o subordinado a obedecer integralmente às regras institucionais e às ordens dos superiores, visto que se trata de utilizar, na polícia, regras semelhantes às utilizadas nas Forças Armadas". (COSTA, 2018, p.40)

No entanto, os alunos não conseguem fazer distinção e compreender que, na universidade, a hierarquia funciona diferente. As sanções, da mesma forma, são distintas e também não recaem sobre o corpo. Todas são de cunho administrativo. Sobre a confusão instaurada pelos alunos, Neves (2016, p.29) faz ainda, algumas considerações:

Nem a expulsão impede ao aluno de entrar na universidade, ele só não terá mais o tratamento de aluno. Dentro dessa relação de obediência da instituição militar, a polícia deveria ter o papel de difundir a obediência às regras na sociedade, porém não está socializada para aderir a novas regras. $\mathrm{O}$ fato da disciplina na instituição militar ter consequências ao corpo faz com que se crie um medo por não respeitar as regras, por não ser disciplinado. A transferência dessa noção para dentro do universo acadêmico não faz nenhum sentido, a partir do momento que nenhuma sanção deve ou pode recair sobre o corpo. A disciplina, para dentro da academia, sendo aquilo que tem a ver com o respeito às regras $\mathrm{e}$ normas instituídas, tem a ver também com uma forma de se pensar disciplinada, pois se vê as coisas a partir de um mesmo ponto de vista. Desta forma, dentro de um programa de Direito, todos são disciplinados a pensar da perspectiva do Direito, a disciplina tem, na universidade, a ver com o saber. (NEVES, 2016, p.29)

Em função dessa hierarquia internalizada vivenciada diariamente em suas práticas profissionais e da dificuldade de compreensão e socialização com as regras acadêmicas, os alunos se queixam e acusam, tanto a universidade quanto o curso, de desorganizados. Esperam, assim, a mesma organização presente nas instituições militares.

Não obstante, os alunos que apresentam o discurso descrito anteriormente, quando falam da necessidade de regras nas instituições escolares, defendem escolas militares, por considerarem que estas atendem a tal necessidade. Discorrem sobre leis e regras, colocando-as em um mesmo patamar, mas, burlam - ou tentam burlar - as regras acadêmicas e institucionais. Refletir sobre a relação dos alunos com as regras do curso é necessário para a compreensão de quem são eles e suas formas de interação.

\section{A violência naturalizada}

A socialização com as regras permite uma grande tolerância por parte dos alunos 
com relação à violência, principalmente porque a violência faz parte de suas práticas, como também faz parte de suas interações, assim, é exibida de várias formas como se pode observar em mais uma descrição.

É nos dias de prova presencial que essas situações são mais recorrentes, tendo em vista que são os momentos em que existe a presença de todos os alunos no polo diferente das tutorias, em que há presença reduzida (o que não faz com que os conflitos não ocorram).

Em mais um dia de prova, uma tarde de sábado, uma das autoras estava em sala aplicando prova. Iniciei o momento dando as orientações iniciais quando um aluno chegou, cumprimentou a mim e aos colegas que estavam mais próximos. Sentou-se em uma carteira na primeira fileira, em frente à mesa onde eu estava posicionada e, naturalmente, retirou uma arma da cintura colocou sobre a mesa. Retirou uma caneta, um lápis e uma borracha do bolso e também os colocou sobre a mesa. Retirou a arma de cima da mesa e a colocou entre as pernas deixando-a ali. Recebeu a prova e começou a preencher o cabeçalho.

Ao terminar de entregar as provas, retornei para a mesa e comecei a observar os alunos. Uma aluna que estava sentada ao lado do aluno que estava com a arma, olhava para mim, arqueava as sobrancelhas e olhava para a arma. Dirigi-me até ela e em um tom de voz muito baixo, quase sussurrando falou: "Tô nervosa com essa arma. Tá me incomodando".

Então solicitei que o aluno guardasse a arma. Ele disse que não tinha onde guardar, pois havia deixado a mochila no carro. Solicitei que o tutor que estava no apoio o acompanhasse até o carro para que ele pudesse pegar a mochila. Ele retornou para a sala com a mochila e a arma guardada. Ele e a outra aluna continuaram fazendo a prova normalmente. Em nenhum momento, o aluno questionou ou se incomodou com a solicitação. Ao terminar a prova, a aluna me pediu desculpas, mas disse que havia ficado nervosa com a arma. Esse relato demonstra o quanto algumas ações estão naturalizadas pelos alunos, fazendo com que não reflitam sobre elas em um ambiente que não é o de trabalho. Nesse sentido, Veríssimo pondera que:

No "caso da arma", a naturalização do aluno com o fato de nunca deixar de estar portanto sua pistola é tamanha que aparentemente não o deixa notar que isso pode ser uma coisa que, embora natural para ele, pode estar longe de sê-lo na universidade. (VERÍSSIMO, 2015, p.13)

A linguagem corporal e oral dos alunos, em muitas situações no Polo, são a mesma utilizada por esses em suas práticas militares. Como demonstra mais um relato. 
Enquanto os alunos chegavam para a realização de provas na parte da tarde, uma das autoras, não estava em sala e sim no "apoio". Neste momento, alguns alunos estavam em sala de aula estudando e outros conversavam no corredor. Estava encostada em uma mesa no corredor conversando com outro tutor que estava também no apoio e com um aluno, quando um segundo aluno, aquele que portava a arma pela manhã, saiu de uma sala. Ao avistar a autora que faz esse relato falou, com um tom de voz alta: "Ô professora!" e foi em sua direção, parou em sua frente, abriu um pouco as pernas, cruzou os braços e lhe perguntou: "Esse tutor de Oficina é retardado ou é o que?". A autora perguntou de quem ele estava falando e o porquê e ele respondeu: "Esse tutor, ué! Ele me deu nota baixa na AD e na AP. Ele só pode ser retardado. Eu sei que fiz uma boa prova”. Então ela falou com o aluno: "Ih! Eu acho que nós temos dois retardados então, porque quem corrige a $A D$ é um tutor e quem corrige a AP é outro tutor. As avaliações são corrigidas por dois tutores diferentes. E você não tem nenhuma relação com suas notas, né”? Ele respondeu: “Ah é! Eu não sabia...”

A autora confessa que se sentiu tanto intimidada pela postura e pela forma como o aluno a interpelou no corredor quanto pela arma que ele deixou à mostra no momento de realização da prova.

A descrição supracitada exemplifica a violência na forma de tratamento com as pessoas, seja com os seus pares, nesse caso os demais alunos, ao portar a arma mesmo que de forma não ostensiva, como na agressividade de sua fala com relação ao tutor. Assim como os gestos, a construção das demandas com relação a inúmeras questões sempre passa por um processo de violência.

Da mesma forma, o deboche, constante, utilizado pelos alunos é uma estratégia de violência explícita e naturalizada de desqualificação do outro.

Em um dia de semana, véspera da data limite de entrega de uma avaliação a distância de uma determinada disciplina, pude presenciar uma situação um pouco constrangedora para a tutora presencial ao término da aula.

Estava sentada na sala da coordenação atualizando o horário de tutorias presenciais, quando, já quase no final da noite, por volta de $21 \mathrm{~h} 40$, ouvi os alunos saírem da sala de aula acompanhados pela tutora. Não conseguia vê-los, mas ouvia muito bem a conversa.

$\mathrm{Na}$ ocasião, a tutora tentava tranquilizá-los com relação à avaliação dizendo que eles estavam bem preparados 
e que conseguiriam fazer a atividade sem problemas, quando um dos alunos falou: "Professora! Corrige a minha prova com carinho. Lembra que eu posso encontrar a senhora em uma blitz". A tutora "visivelmente" sem graça brincou e falou que não tinha carro. $\mathrm{O}$ aluno então disse: "Posso parar o carro do seu namorado". E, mais uma vez, a tutora respondeu, dessa vez, em um tom mais sério: “Eu não tenho namorado". A tutora se virou e extremamente constrangida, com as bochechas vermelhas e a voz trêmula, me disse: "Acho que isso não foi só uma brincadeira. Ainda bem que eu não tenho carro ou então ficaria com medo de ser abordada por ele na rua".

Esses gestos de violência explícita são naturalizados e repetidos. Os instrumentos da universidade são ineficazes para tratar dessa violência. No contexto militar, a violência somente pode ser detida com a prisão ou por ordem de um superior e, na Universidade, não funciona desta forma. Mesmo que o coordenador possa ser visto como um superior, não há eficácia simbólica uma vez que nenhuma ação deste pode gerar mudança nessas atitudes. A Universidade constitui um ambiente acadêmico de interações sociais e essa violência tem a ver com a socialização com as regras.
Diferente das instituições onde o castigo e a culpabilização são práticas comuns presentes desde a criação das instituições polícia militar e polícia civil (KANT DE LIMA, 2013; HOLLOWAY, 1997), a prática dessas instituições existentes atualmente ainda apresentam características do império. Essa reflexão contribui para o entendimento acerca da hierarquia na polícia militar e dos anseios em atender às demandas da classe dominante, caracterizando a desigualdade existente desde aquela época.

Observa-se que, no curso, da mesma forma como em suas práticas profissionais, os alunos procuram culpados para as dificuldades encontradas, enquanto, no ambiente acadêmico, a prática realizada é a responsabilização.

Essa responsabilização está relacionada à sensibilidade jurídica civil law tradition, na qual, através de códigos legais legitimados pelo poder legislativo, pela construção de consensos temporários de forma sucessiva e pela interpretação dos fatos em um processo de inquirição, buscase a verdade e não a culpa (KANT DE LIMA, 2013). 


\section{Hierarquia das instituições militares \\ Hierarquia na \\ Universidade}

- Hierarquia da obediência

- Princípio de organização, disciplina e punição

- "manda quem pode e obedece quem tem juízo. Na polícia não tem questionamento, diálogo. É tudo muito organizado e ordenado. A gente só obedece."
- Hierarquia funciona de forma horizontal.

- hierarquia de comando único.

- hierarquia é administrativa e está subordinada ao princípio da liberdade acadêmica, que só pode ser limitada pelos próprios pares.

Quadro elaborado e apresentado pela autora Érika Guimarães Ferreira em uma palestra na II Jornada Acadêmica do Polo Nova Friburgo em 2019.

Pensar na lógica proposta por Geraldo e Kant de Lima (2015) possibilita a compreensão da conduta desses alunos, eles pertencem a um grupo onde a violência é totalmente naturalizada e, da mesma forma, produzem violência em suas relações sociais e acadêmicas, performando-se a partir de seus gestos naturalizados. Estão submetidos a um poder violento e consequentemente submetem os demais com os quais se relacionam em qualquer instância da sociedade, com exceção dos juízes com os quais demonstram subalternidade.

A violência para os alunos é tão naturalizada que, mesmo considerando equivocada algumas atitudes, os demais não interferem, ficam aguardando e relatam que se acontecesse algo a mais como agressão física tomariam alguma atitude, como se sua atitude não fosse violenta o suficiente para uma intervenção.

Atitudes pontuais assim como a postura física dos alunos ao andarem pelo polo intimidam tutores e alunos de outros cursos. Em função desse tipo de atitude alguns tutores não se sentem à vontade para manter uma relação mais próxima com os alunos. O que nos faz refletir acerca das ações típicas e consequências dessas ações nos processos de socialização. Segundo Platero e Vargas (2017), tipificações e estoques de conhecimento à mão levam o policial a interpretar o que ele vê e outras pessoas não veem. É deste estoque de conhecimento dos alunos em contraposição ao estoque de conhecimento dos tutores que se originam muitos conflitos.

Pensando a partir da abordagem de Schutz, poderia trabalhar os exemplos 
relatados elaborando uma tipologia das ações típicas e atípicas. Porém, muitos dos exemplos apresentados para uma reflexão sobre a socialização com as regras e consequentemente acadêmica, ao menos nas outras graduações oferecidas no Polo, se apresentariam como atípicas. No Tecnólogo, se constituem em ações e comportamentos típicos, característicos e próprios do processo de socialização acadêmica desses alunos uma vez que, em proporções diferentes, se apresentem de forma corriqueira.

Nos últimos semestres, o perfil dos alunos que ingressam no curso, assim como a forma de administração dos conflitos, foram se aprimorando e, com isso, os conflitos foram minimizados.

\section{Uma praça no mestrado! Uma análise de um caso concreto}

Uma das pesquisadoras autoras deste trabalho é doutoranda e policial militar no estado do Rio de Janeiro, esta seção irá apresentar a situação conflitante quando a praça foi aprovada no processo seletivo para o mestrado.

Tão logo teve ciência do resultado de aprovação no processo seletivo para o Programa de Pós-Graduação em Sociologia e Direito na Universidade Federal Fluminense, o subcomandante ficou visivelmente contente e disse não saber como proceder, tendo em vista que, seria necessário a liberação dos dias do expediente para cursar a pós-graduação. Neste ímpeto, sugeriu que a policial realizasse contato com a Diretoria Geral de Ensino e Instrução (DGEI).

Na Diretoria, em contato com um oficial superior, esta esclareceu as dúvidas. Disse que após a matrícula na universidade, a policial deveria fazer um processo que se iniciaria com um requerimento pontuando incentivo à qualificação profissional. No momento em que o processo chegasse àquela Diretoria, fariam contato telefônico, concomitantemente, com o comandante da unidade e o diretor da DGEI, de forma a agendar um dia propício para a apresentação do pré-projeto à uma banca. Esta banca seria formada pelos dois comandantes supracitados, alguns oficiais da DGEI. A banca julgaria se a temática é pertinente ou não para a instituição.

Em caso positivo, a obtenção da liberação para frequentar as aulas, caso contrário, não. Se positivo, passaria a integrar o Programa de incentivo à qualificação profissional. O oficial superior disse também que, exerce a mesma função há oito anos, na diretoria de ensino, e que este caso era o quarto caso de policial solicitando dispensa para cursar pósgraduação stricto sensu. O que nos faz concluir que, ou os policiais não se vêem 
atraídos por tal segmento acadêmico ou o fazem sem o conhecimento da polícia, o que acarretaria complicações quanto a realização das atividades do curso.

O requerimento foi feito e o processo montado, era um processo inédito na unidade o que justifica as dúvidas que surgiam por parte dos operadores responsáveis pela elaboração de tal instrumento. Poucos dias após o envio, a banca fora agendada.

No dia agendado, o diretor da divisão de ensino deu início à banca que era formada por ele, pelo comandante da unidade onde a praça serve, por um capitão da divisão de ensino e a praça. Com as portas fechadas, o diretor fez um pronunciamento inicial destacando a importância de o policial se qualificar. Ao abrir a pasta que continha meu pré-projeto, ele se ateve à universidade e disse: "É você vai pra UFF, né, lá eles gostam de criticar a gente. Pelo menos com você, seremos criticados por alguém da casa". Esta fala soou repleta de controle social, porquanto não pudesse "criticar" a polícia no mesmo patamar de igualdade que um pesquisador paisano (designação para quem não é policial), tendo em vista a obediência às normas.

Ao ler o título, o coronel que conduzia a banca perguntou qual seria o interesse em estudar abordagem policial ao usuário de drogas. Foi argumentado que o comportamento do policial em relação ao usuário deve ser revisto tendo em vista que a forma como é feita não se faz pertinente na atual sociedade.

O diretor então perguntou qual seria a aplicabilidade do estudo na polícia e disse que poderia ser utilizado para rever o currículo dos cursos de formação ofertados pela instituição. Após as perguntas pertinentes ao pré-projeto, ele se vira para o comandante da unidade (que a policial serve) o diz que o procedimento protocolar seria a transferência da unidade atual para a DGEI e lá ser destacada em uma unidade que possibilite o campo de pesquisa. Neste momento, perguntou para que unidade a policial gostaria de ir, se Batalhão de Operações Especiais (BOPE), Batalhão de Choque ou Coordenadoria de Polícia Pacificadora (CPP). Esta fala apresenta um sistema de classificação em que somente estas unidades poderiam fornecer o campo necessário para a pesquisa envolvendo policiais nas abordagens aos usuários de drogas. Como se o enlace policial, abordagem e usuários de drogas ocorresse somente nestes batalhões.

Ao término da banca, que durou cerca de trinta minutos, o diretor autorizou as dispensas e, ao se despedir, disse que a realização de uma pesquisa em nível mestrado por uma praça iria dar trabalho para a polícia por duas razões: primeiro na parte administrativa, que implica a liberação de 
serviços extras, limitando a carga horária aos dias (de segunda a sexta-feira) que não tenha atividade acadêmica, não podendo exceder o horário do expediente ( $9 \mathrm{~h}$ às 17/18h); e, segundo, porque a referida policial pensa, o que parecer ser contra a lógica da instituição em relação às suas praças.

Conviver com essa liberação não foi fácil. Ao mesmo tempo que as praças viam de forma positiva a liberação, tendo em vista os estudos, os oficiais preferiam "fingir que não estavam vendo". No referido batalhão, ninguém possui formação em nível stricto sensu. Poucos são os oficiais que possuem graduação além do Curso de Formação de Oficiais que, após 1999, deixou de ser considerado pelo MEC como ensino superior, segundo afirmação do Comandante Geral da época, em uma palestra.

No âmbito das praças, um número significativo possui graduação, oriundo de universidade particular, com ênfase para o curso de direito, outro número considerável cursa ou concluiu o curso Tecnólogo em Segurança Pública pela UFF na modalidade semipresencial. Algumas praças com especialização, também oriundos de instituição particular e de alguns que, destoando da necessidade de se aproximar da linguagem do Estado ou ainda não se aproximando dos estudos pertinentes à Segurança Pública, estudam engenharia e arquitetura.
Ao término do mestrado, em contato com a Diretoria de Ensino e Instrução da Polícia Militar do Estado do Rio de Janeiro, a resposta foi que não seria possível nenhum tipo de auxílio e que seria necessário, a praça em questão "dar seu jeito", o que refletiu um desinteresse em que a praça conclua seus estudos em nível de doutorado.

\section{Considerações finais}

As observações e descrições apresentadas neste artigo, demonstram que muitos alunos entraram no curso de Tecnólogo em Segurança Pública e Social ofertado pela Universidade Federal Fluminense aos operadores de segurança pública com a expectativa de confirmar o que aprenderam na prática diária no exercício de suas funções. Ao iniciar o curso, eles se depararam com discussões complexas sobre a Segurança Pública do ponto de vista da sociedade e a forma ampla que constroem as diferentes concepções de sociedade, assim como os fatores envolvidos nessa construção. O confronto das moralidades civil e o ethos policial se inicia desta forma.

$\mathrm{Na}$ proposta do curso e em sua metodologia, se pluralizam ao longo do curso e na relação de ensino e aprendizagem. Diferente da concepção de hierarquia presente nas instituições militares - como princípio de organização, disciplina e 
punição - na universidade, a hierarquia funciona de forma horizontal. Ao passo que, a instituição oferece um incentivo à qualificação "limitado" pois, se por um lado é interessante incentivar a qualificação da praça policial militar não é interessante que este se destaque.

O trabalho enlaça reflexões e críticas acerca das profissões jurídicas, neste recorte, o policial militar que figura como operador de segurança pública e como aquele profissional que seleciona, através de um ethos, aqueles que merecem maior vigilância e os que estão aptos a ingressar no sistema criminal.

No que diz respeito ao processo hierárquico no âmbito acadêmico observamos que, embora os alunos, por vezes solicitem uma relação de privilégios dentro desse espaço, demandam para esse o processo de hierarquização militar. Não percebem que nas universidades, a hierarquia é distinta da hierarquia militar. Por não terem essa compreensão em muitas situações consideram a hierarquia inexistente na academia e, consequentemente, tentam fazer valer no espaço universitário a hierarquia militar da qual são oriundos.

No desenvolvimento desta pesquisa observamos o conflito de hierarquias existente num primeiro momento quando o processo de formação das praças que não privilegia a reflexão e na sequência, quando a praça possui um nível de formação acadêmica. Se por um lado, existe um estímulo ainda recente da instituição em relação a qualificação das praças, por outro a mesma instituição se vê numa situação conflituosa quando se depara com a praça instruída academicamente.

\section{Referências bibliográficas}

\section{CARUSO, Haydée G. C. Das práticas e} dos saberes: a construção do fazer policial entre as praças da PMERJ. Dissertação (Mestrado em Antropologia Social) Universidade Federal Fluminense, Niterói, 2004.

CARUSO, Haydée. PATRÍCIO, Luciane. PINTO, Nalayne. Polícia Militar do Estado do Rio de Janeiro: da Escola de Formação à Prática Policial. In: Encontro Anual da Associação Nacional de Pós Graduação e Pesquisa em Ciências Sociais, XXX, 2006, Caxambu. Anais 30 ANPOCS. São Paulo: ANPOCS, 2006. v.1.

COSTA, Perla Alves Bento de Oliveira. Quando a gansóloga sou eu: Uma etnografia sobre as práticas dos policiais militares no Rio de Janeiro. Dissertação (Mestrado em Sociologia e Direito) Universidade Federal Fluminense, Niterói, 2018.

FERNANDES, N. K. Q., De policial a estudante: uma análise do processo de socialização dos alunos na universidade. Monografia (Bacharelado em Segurança Pública) - Universidade Federal Fluminense, Niterói, 2016.

FERREIRA, É. G., Na faculdade a gente aprende a pensar: uma análise da socialização acadêmica dos alunos do Curso de Tecnologia em segurança Pública e 
Social. Dissertação (Mestrado em Sociologia e Direito) - Universidade Federal Fluminense, Niterói, 2019.

FOUCAULT, Michel. Microfísica do Poder. Organização e tradução de Roberto Machado. 18 ed. Rio de Janeiro: Edições Graal, 2006.

GERALDO, Pedro Heitor Barros, KANT, de Lima. Administração de Conflitos em Perspectiva Comparada. In: Encontro Anual da Anpocs, XXXIX, Caxambu, 2015.

GEERTZ, Clifford. "O saber local: fatos e leis em uma perspectiva comparativa". In: GEERTZ, Clifford. O Saber Local: novos ensaios em antropologia interpretativa. 8a edição. Petrópolis: Vozes, 2008.

KANT DE LIMA, Roberto. Direitos civis, Estado de Direito e "cultura policial": a formação policial em questão. Revista Preleção - Publicação Institucional da Polícia Militar do estado do Espírito Santo de assuntos - Segurança Pública, Vitória, v.1, n.1, abr. 2017.

\section{A Antropologia da}

Academia: Quando os índios somos nós. Niterói : Eduff, 2011.

\section{Entre as leis e as}

normas : éticas corporativas e práticas profissionais na segurança. Dilemas Revista de Estudos de Conflito e Controle Social, Rio de Janeiro, v. 6, n. 4, p. 549-580, 2013.

MALINOWSKI, Bronislaw. Argonautas do Pacífico Ocidental: um relato do empreendimento e da aventura dos nativos nos arquipélagos de Nova Guiné melanésia. Traduções de Anton P. Carr e Lígia Aparecida Cardieri Mendonça; revisão de Eunice Ribeiro Durham. 2. ed. São Paulo: Abril S.A. Cultural e Industrial, 1978.

MUNIZ, Jacqueline de Oliveira. Ser Policial é sobretudo uma razão de ser.
Cultura e Cotidiano da PMERJ. Tese (Doutorado em Ciência Política) - Instituto Universitário de Pesquisas do Rio de Janeiro (IUPERJ), Rio de Janeiro, 1999.

NEVES., D. M. C. Hierarquia e

disciplina: análise da relação de ensinoaprendizagem no curso de Tecnólogo e Segurança Pública e Social. Monografia (Bacharelado em Segurança Pública) Universidade Federal Fluminense, Niterói, 2016.

OBERLING, A. F., Maconheiro, dependente, viciado ou traficante?

Representações e práticas da Polícia Militar sobre o consumo e o comércio de drogas na Cidade do Rio de Janeiro. Dissertação (Mestrado em Antropologia) Universidade Federal Fluminense, Niterói, 2011.

PLATERO., K. e VARGAS, J. O que foi que aconteceu?, Dilemas - Revista de Estudos de Conflito e Controle Social, Rio de Janeiro, v.10, n.3, 2017, p. 621-641.

SCHUTZ, A. Fenomenologia e relações sociais: Textos Escolhidos de Alfred Schutz. Organização Helmut R. Wagner. Tradução de Ângela Melin. Rio de Janeiro: Jorge Zahar Editores, 1979.

SILVA, Robson Rodrigues da. Entre a caserna e a rua: o dilema do "pato": Uma análise antropológica da instituição policial militar a partir da Academia de Polícia Militar D. João VI. Niterói : Eduff, 2011.

VERÍSSIMO, Marcos. Quando a Polícia vai à Faculdade: "inclusão social" ou "choque cultural"? In Congresso Brasileiro de Sociologia, XVII, 2015, Porto Alegre. Apresentação de trabalho. 